\title{
SERVIÇOS ECOSSISTÊMICOS DE PROVISÃO DO MANGUEZAL DA RESERVA DE DESENVOLVIMENTO SUSTENTÁVEL ESTADUAL PONTA DO TUBARÃO (MACAU-RN)
}

\author{
Dayane Raquel da Cruz Guedes ${ }^{(a)}$, Ivaniza Sales Batista ${ }^{(b)}$, Luiz Antonio Cestaro ${ }^{(\mathrm{c})}$, Diógenes \\ Félix da Silva Costa $^{(\mathrm{d})}$
}

\footnotetext{
(a) Mestranda pelo Programa de Pós-graduação e Pesquisa em Geografia (PPGE), Universidade Federal do Rio Grande do Norte, dayane.geo10@gmail.com

(b) Mestranda pelo Programa de Pós-graduação e Pesquisa em Geografia (PPGE), Universidade Federal do Rio Grande do Norte, ivanizas@ymail.com

(c) Docente Permanente do Programa de Pós-graduação e Pesquisa em Geografia (PPGE), Universidade Federal do Rio Grande do Norte, lacestaro@cchla.ufrn.br

${ }^{\text {(d) }}$ Docente Permanente do Programa de Pós-graduação e Pesquisa em Geografia (PPGE), Universidade Federal do Rio Grande do Norte, diogenes.costa@ pq.cnpq.br
}

\section{Eixo: BIOGEOGRAFIA, MANEJO DE ÁREAS NATURAIS E PROTEGIDAS: CONSERVAÇÃO DA BIODIVERSIDADE}

\begin{abstract}
Resumo
O manguezal proporciona serviços ecossistêmicos para as comunidades humanas que habitam o entorno desses ambientes. Neste trabalho objetivou-se identificar os serviços ecossistêmicos de provisão prestados pelo manguezal na Reserva de Desenvolvimento Sustentável Estadual Ponta do Tubarão. A identificação dos serviços ecossistêmicos de provisão (matéria, energia e nutrição) foi realizada a partir da classificação CICES (Classificação Internacional Comum para Serviços de Ecossistemas), consultando literatura produzidos para a área de estudo e realizando observações locais. Os resultados encontrados consistem numa tabela com três classes de serviços de provisão: plantas nativas, animais nativos e fibras/materiais de algas, de plantas e animais para uso direto ou transformação. Não se observou a utilizaçao de materia do manguezal para a obtenção de energia (lenha e/ou carvão). A partir da identificação dos serviços foi possível observar que o ecossistema de manguezal é importante para as comunidades locais que se beneficiam de forma direta e indireta dos bens e serviços prestados pelo manguezal.
\end{abstract}

Palavras chave: Manguezal, Serviços Ecossistêmicos, CICES.

\section{Introdução}

O manguezal é um ecossistema costeiro, de transição entre os ecossistemas marinho e terrestre é sujeito ao regime de marés. Apresenta uma importância que vai além do aspecto ecológico, pois muitas comunidades que vivem no litoral tiram seu sustento dos manguezais através da pesca artesanal e de subsistência, sendo fonte de renda necessária à sua sobrevivência (VANNUCCI, 2002).

Apesar dos muitos benefícios dos manguezais, eles são alvo de pressões antrópicas, mesmo tendo a proteção prevista pelos órgãos legais vigentes. Os manguezais brasileiros em geral vêm sofrendo um 
intenso e constante processo de degradação, que resulta no comprometimento dos serviços (FONSECA; DRUMMOND, 2003). No entanto, se torna imprescindível o conhecimento dos serviços para compreender a importância dos manguezais para a população, que retiram do ecossistema fontes de renda para a sobrevivência.

O manguezal proporciona uma série de serviços ecossistêmicos (SE) necessários para a manutenção das comunidades humanas que habitam o entorno desses ambientes. Considerados como um dos mais produtivos do planeta, este ecossistema propicia alguns serviços como a proteção das margens do estuário, o fornecimento de recursos vegetais e animais para populações humanas, retenção de sedimentos e substâncias químicas (COSTA; CESTARO; DE MEDEIROS ROCHA, 2014).

A abordagem através dos serviços ecossistêmicos auxilia na sensibilização sobre a relação de dependência da sociedade e dos ecossistemas em equilíbrio, colaborando para demonstrar a importância da conservação da natureza. Assim, fica explícito o vínculo entre sistemas físicos e sistemas humanos, ambos interagindo de forma dinâmica com os ecossistemas (BALVANERA, 2009). Mediante a importância dos manguezais, esses ambientes são poucos valorizados no que diz respeito a proteção desse ecossistema e no Rio Grande do Norte, tem sido submetidos a intensas pressões antrópicas. Em busca de minimizar essas ações que ocorria em Ponta do Tubarão, o Governo do Estado criou a Reserva de Desenvolvimento Sustentável (RDS). Neste sentido, apresenta-se como estudo de caso o sistema de manguezal na RDSEPT, originada pela Lei $\mathrm{n}^{\mathrm{o}} 8.349$ de 18 de julho de 2003, na qual define como uma área protegida para buscar a conservação do ambiente e o uso sustentável dos recursos naturais, criada através dos esforços da população caiçara, no Rio Grande do Norte (RN).

A RDSEPT abrange uma área de aproximadamente 12.940 hectares, localizada entre os múnicipios de Macau e Guamaré (FIGURA 1). Estes municípios estão situados na mesorregião Central Potiguar e inseridos na Microrregião Homogênea de Macau, representados nas folhas Macau I (SB.24-X-D-II) e São Bento do Norte (SB.24-X-D-III), na escala 1:100.000, apresentam distância aproximada de $190 \mathrm{~km}$ de Natal, capital do estado (SUDENE, 1969). 


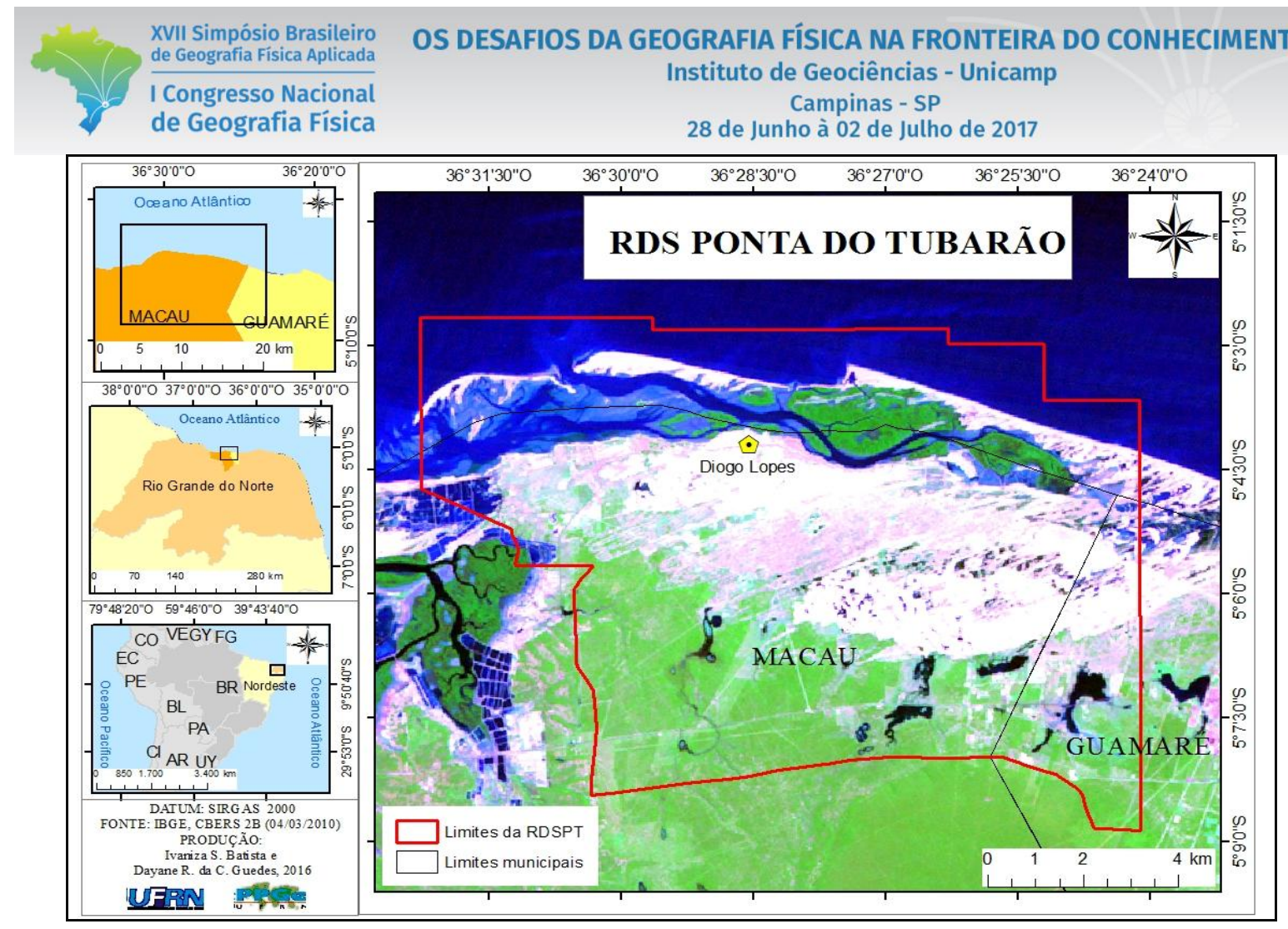

Figura 1 - Localização da área de estudo

Fonte - Base de dados do IBGE e CBERS 2B

Esta unidade de conservação abrange seis comunidades tradicionais que estão inseridas nos limites da Reserva: as comunidades pesqueiras de Diogo Lopes, Barreiras e Sertãozinho (pertencentes à Macau) e as comunidades agrícolas de Mangue Seco I e II e Lagoa Doce (pertencentes à Guamaré). A área possui clima semiárido, com altas taxas de evaporação e baixo índice pluviométrico (média anual de 537,5 mm) (DIAS; ROSA; DAMASCENO, 2007; IDEMA, 1999).

Diante disso, objetivou-se identificar os serviços ecossistêmicos de provisão prestados pelo ambiente de manguezal na RDSEPT e classifica-los de acordo com tabela CICES (2010).

\section{Procedimentos Metodológicos}

Para alcançar o objetivo proposto, foi utilizado como conceito chave, o aporte teórico elaborado pelo sistema de classificação CICES (Common International Standard for Ecosystem Services) (2010). O estudo foi realizado através de levantamentos de dados de campo e cruzamento de informações científicas já publicadas sobre a área da RDSEPT. No artigo foi trabalhado os serviços de provisão que incluem os produtos e materiais obtidos a partir do ecossistema. Isso se deve ao fato de ser o serviço que apresenta importância no contexto social e econômico das comunidades locais. Como a tabela da CICES foi 
desenvolvida para identificar os serviços de todos os ecossistemas, nesse artigo a tabela será adaptada aos serviços que são fornecidos pelo ecossistema manguezal.

A tabela CICES é organizada de forma hierarquizada onde trabalha em diferentes escalas, partindo do mais geral para o mais específico (FIGURA 2). A seção, é o nível mais alto e o mais genérico desta estrutura, compreendem três grupos distintos: serviços de provisão, serviços de regulação e manutenção, e serviços culturais. Desta forma, o CICES segue uma estrutura hierárquica como forma de permitir aos usuários selecionar o nível mais adequado para a aplicação da pesquisa (SOUZA et al., 2016).

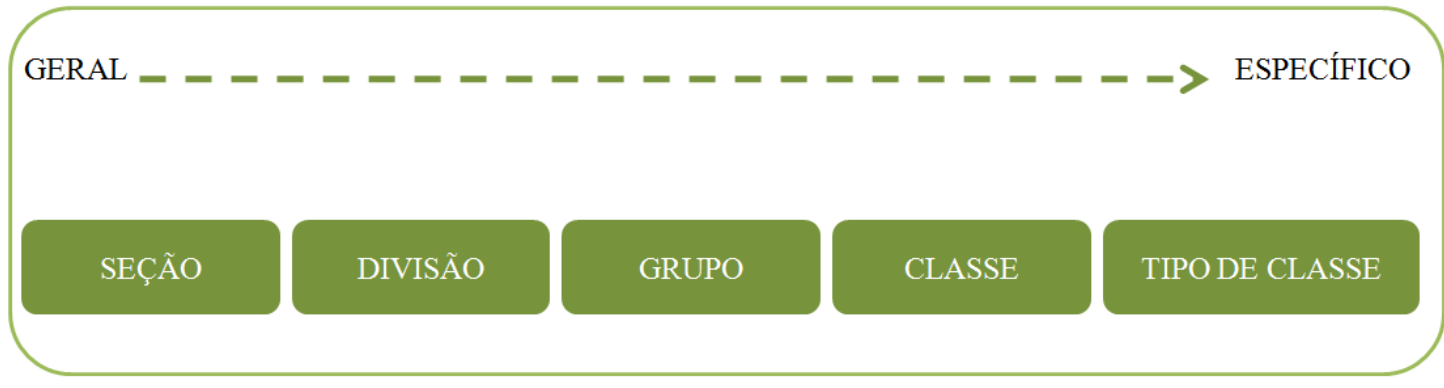

Figura 2 - Estrutura hierárquica da classificação CICES

Fonte - Adaptado de RABELO, 2014.

Foi realizada a elaboração da listagem dos serviços ecossistêmicos de provisão associados ao manguezal, consultando literatura produzidos para a área de estudo e realizando observações locais. Análise do material bibliográfico, partiu de pesquisas científicas específica da área de estudo, como Dias et al., (2007); Mattos et al., (2012); Rocha Júnior (2011) e Queiroz et al., (2014) e a visita de campo ocorreu no período de 28-29 de abril de 2016.

\section{Resultados e Discussões}

A RDSEPT possui uma área de 12.960 ha, na qual os manguezais ocupam uma área hoje de aproximadamente 530,18 ha, representando 4,4\% da área da RDSEPT (FIGURA 3). 


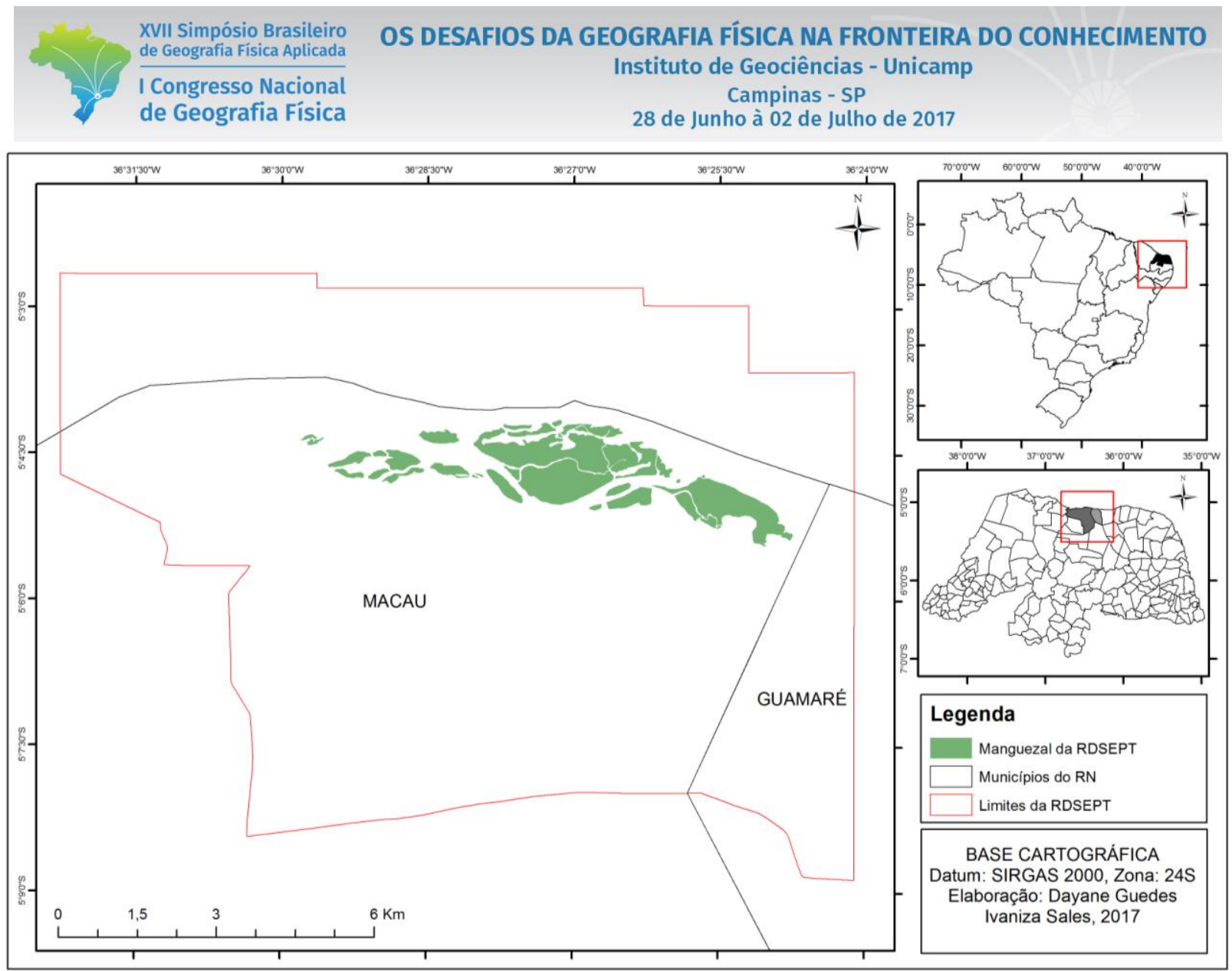

Figura 3 - Área de manguezal na RDSEPT.

A partir de uma revisão bibliográfica foram levantados os serviços ecossistêmicos dos manguezais presentes na área de estudo. O quadro II apresenta os resultados desta pesquisa, divididos nas categorias de serviços ecossistêmicos propostas pela CICES (2010). Vale salientar que os quadros foram modificados, pois nem todos os serviços, proposto pela CICES se aplica na área de estudo, nessa primeira etapa.

Os serviços de provisão elencadas no quadro II, são os que incluem os produtos e materiais obtidos a partir do ecossistema. Contudo, abrange duas categorias de divisão, a nutrição e materiais distribuídos em três classes, as plantas selvagens, algas; animais selvagens e fibras/materiais de plantas e animais para uso direto ou transformação. 


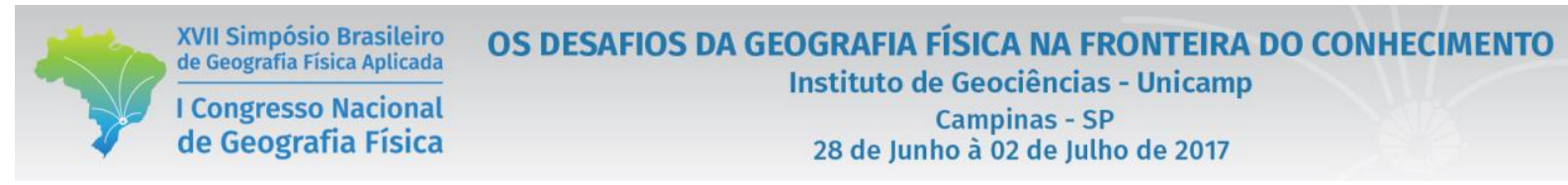

Quadro II - Serviços ecossistêmicos de provisão.

\begin{tabular}{|c|c|c|c|c|c|}
\hline SESSÃO & DIVISÃO & GRUPO & CLASSE & $\begin{array}{c}\text { TIPOS DE } \\
\text { CLASSE }\end{array}$ & AUTORES \\
\hline \multirow{3}{*}{ 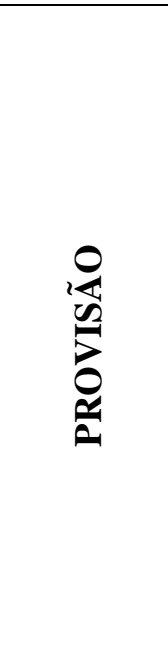 } & & & $\begin{array}{c}\text { Plantas } \\
\text { selvagens, algas }\end{array}$ & $\begin{array}{c}\text { Folha para o } \\
\text { gado }\end{array}$ & $\begin{array}{l}\text { Dias et al. } \\
(2007)\end{array}$ \\
\hline & NUTRIÇÃO & Biomassa & $\begin{array}{l}\text { Os animais } \\
\text { selvagens }\end{array}$ & $\begin{array}{c}\text { Caranguejo- } \\
\text { uça, camarão, } \\
\text { siris, ostras, } \\
\text { cavalo- } \\
\text { marinho, peixe } \\
\text { agulha, } \\
\text { moluscos }\end{array}$ & $\begin{array}{c}\text { Cunha } \\
\text { (2006), Dias } \\
\text { et al. (2007), } \\
\text { Queiroz } \\
\text { (2014), } \\
\text { Rocha Jr. } \\
\text { (2011) }\end{array}$ \\
\hline & MATERIAIS & Biomassa & $\begin{array}{l}\text { Fibras/materiais } \\
\text { de plantas e } \\
\text { animais para uso } \\
\text { direto ou } \\
\text { transformação }\end{array}$ & Madeira & $\begin{array}{c}\text { Nobre } \\
\text { (2005), Dias } \\
\text { et al. (2007), } \\
\text { Mattos et al. } \\
\text { (2012) }\end{array}$ \\
\hline
\end{tabular}

Fonte - Adaptado de Haines-Young e Potschin, 2013

Na classe de plantas selvagens e algas, Dias; Rosa; Damasceno (2007) colocam que a folha das espécies de mangue é utilizada pelos moradores das comunidades como alimento para o gado caprino e equino. $\mathrm{Na}$ qual, algumas espécies vegetais possuem glândulas secretoras de sal como forma de adaptação para eliminar o excesso de sal que fica presentes em suas folhas (YE et al., 2005). O sal desempenha um papel importante na vida dos animais, sendo que o sal encontrado nas folhas de mangue se torna suficiente para as necessidades fisiológicas do animal.

Os manguezais são considerados os principais responsáveis pela manutenção de boa parte das atividades pesqueiras das regiões tropicais. Para as comunidades que vivem próximas aos manguezais, os moluscos representam um dos grupos de maior relevância econômica. Nessas áreas, a coleta desses animais pode se constituir na principal fonte de renda das famílias envolvidas ou como complemento de outras atividades extrativistas (DIAS; ROSA; DAMASCENO, 2007; ROCHA JR., 2011). A pesca ainda é a atividade mais importante na Reserva e envolve cerca de 1.000 famílias que incluem pescadores e pescadoras de peixes, catadores de caranguejo e marisqueiras (DIAS; ROSA; DAMASCENO, 2007) (FIGURA 4). 


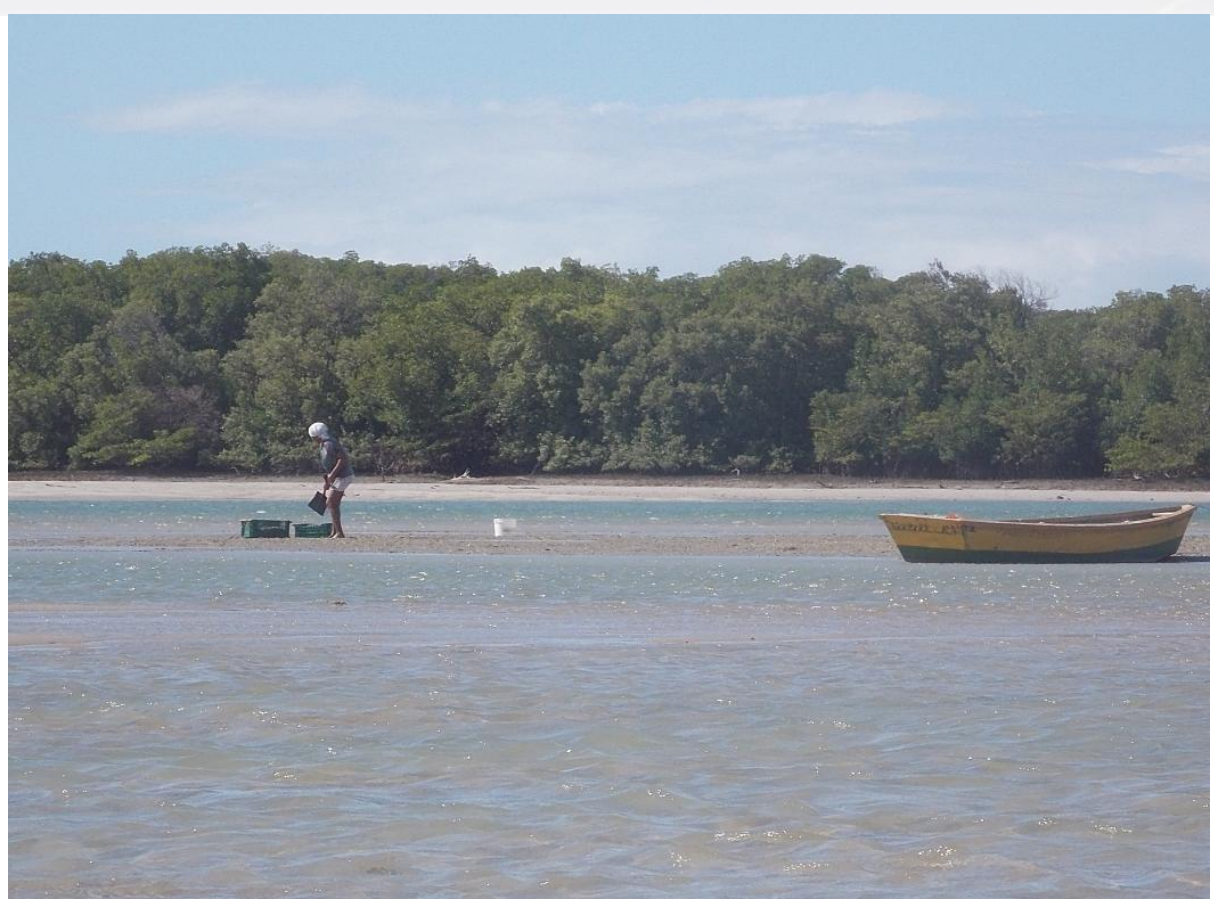

Figura 4 - Marisqueiras coletando os moluscos na RDSEPT

Para Queiroz e Dias (2014), a RDSEPT apresenta um total de 1.490 moluscos pertencentes a 29 famílias foram registradas nas amostras da pesquisa. Os moluscos citados foram o búzio ou marisco (Anomalocardia brasiliana Gmelin, 1791), búzio grande (Lucina pectinata Gmelin, 1791), sururu (Mytella guyanensis Lamarck, 1819) e a ostra (Crassostrea sp.). Na região, o molusco bivalve A. brasiliana é amplamente comercializado, os demais são pouco comercializados e capturados para consumo próprio.

Já nas pesquisas de Mattos et al. (2012), foi demonstrado a percepção da importância do manguezal para a população caiçara e que o caranguejo é considerado o principal ou na maioria dos casos seu único meio de subsistência. Dentre os crustáceos, destacaram-se o caranguejo-uçá (Ucides cordatus Linnaeus, 1763), guaiamum (Cardisoma guanhumi Latreille, 1852), siri azul (Callinectes danae Smith, 1869), siri-lodo (Callinectes sp.), camarão (Penaeidae), aratu (Goniopsis cruentata Laitrelle, 1803) e chama-maré (Uca spp.).

Já com relação aos peixes citados nos trabalhos de Dias; Rosa; Damasceno (2007) e Rocha Jr. (2011), foram identificados a tainha (Mugil spp.), dentão (Lutjanus jocu Bloch \& chineider, 1801), cavalomarinho (Hippocampus reidi Ginsburg, 1933), pacamão (Amphichthys criptocentrus Valenciennes, 1837), muriongo (Myrichthys ocellatus Lesueur, 1825) e anequim (Thalassophryne nattereri Steindachner, 
XVII Simpósio Brasileiro

de Geografia Física Aplicada

I Congresso Nacional

de Geografia Física

\section{OS DESAFIOS DA GEOGRAFIA FÍSICA NA FRONTEIRA DO CONHECIMENTO \\ Instituto de Geociências - Unicamp \\ Campinas - SP \\ 28 de Junho à 02 de Julho de 2017}

1876). Dias; Rosa; Damasceno (2007) registrou na região um total de 50 espécies de peixes, pertencentes a 38 gêneros e 30 famílias, sendo Gerreida e e Lutjanida e as famílias com maior número de espécies.

Já com relação a fibras/materiais de plantas e animais para uso direto ou transformação utilizadas na RDSETP, Dias; Rosa; Damasceno (2007) e Nobre (2005) afirmam que a madeira, principalmente a Rhizophora mangle L. (mangue vermelho) é utilizada na construção de casas de taipa, ranchos de pescadores, embarcações, como também lenha para fogões, cercas e embarcações (FIGURA 05). Mattos et al. (2012), também afirmam que as marisqueiras utilizam a madeira da Rhizophora sp. para ferver os mariscos, por ser uma forma economicamente viável.

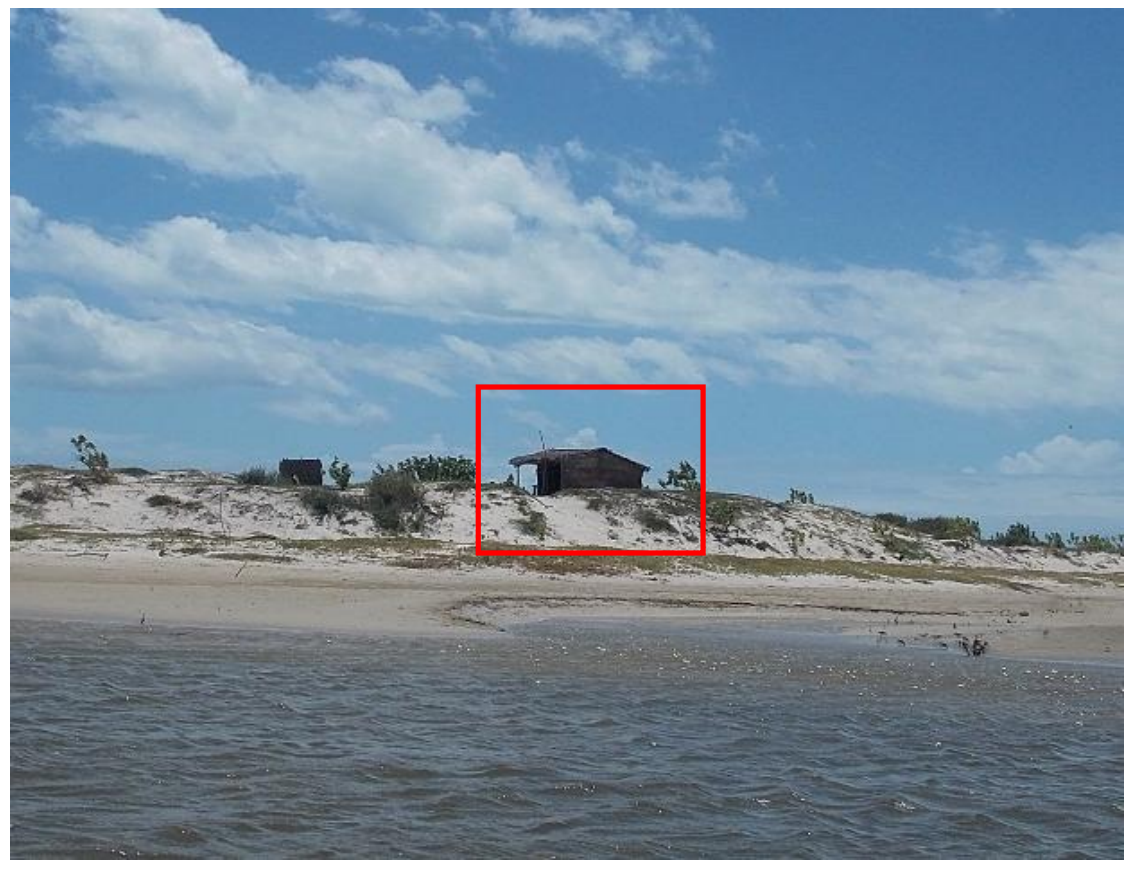

Figura 5 - A - Casas de taipas feitas com madeira da vegetação de mangue, B - Rhizophora mangle.

Na qual Bandaranayke (1998) afirma que dentre as espécies de mangue, o gênero Rhizophora fornece o melhor carvão de lenha com alto poder calorífico, queima lenta e sem fumaça, afirmando os motivos pelos quais é utilizado pelas marisqueiras. Diante disto, os serviços de provisão estão relacionados com os estoques de matéria-prima utilizados pelo homem, garantindo o bem-estar humano. Os produtos originados pelos serviços de provisão podem tanto ser consumidos in natura como podem passar por processos de transformação nas indústrias (MEA, 2005). 


\section{Considerações finais}

A partir da bibliografia é possível observar que o ecossistema de manguezal desempenhada um papel importante, para as comunidades locais que se beneficiam de forma direta e indireta dos bens e serviços prestados pelo manguezal, retirando localmente o sustento de suas respectivas famílias. Vale destacar, que os autores utilizados como referência durante a pesquisa não discutem estes benefícios como serviços ecossistêmicos, apenas analisam a existência e importância destes recursos no contexto ambiental e socioeconômico da área de estudo. No entanto, essas pesquisas deram suporte para a identificação e organização dos serviços prestados pelo ecossistema manguezal, em ambas as áreas.

É incontestável a relevância desempenhada pelos ecossistemas de manguezal no mundo, eles exercem os mais variados tipos de serviços de provisão, regulação/manutenção e cultural, os quais são fundamentais para a saúde e o bem-estar humano, condicionando a sobrevivência das comunidades locadas em sua circunvizinhança, principalmente.

Na RDSEPT, as comunidades locais beneficiam-se direta e indiretamente dos bens e serviços prestados pelo manguezal, retirando localmente o sustento de suas respectivas famílias (serviços de provisão), beneficiando-se dos processos naturais que regulam as condições ambientais e atribuindo valor cultural ao ecossistema, conforme evidenciado nos trabalhos científicos consultados.

É nesse sentido, que se evidência a necessidade da promoção do uso racional e sustentável desse ambiente, visando a conservação do mesmo para o usufruto dos serviços ecossistêmicos prestados pelo sistema de manguezal por parte das comunidades locais atuais e grupos sociais futuros.

Portanto, deve-se reconhecer tais serviços e conscientizar a sociedade sobre sua importância nos âmbitos ambiental e social, pois a conscientização é o primeiro passo para repensar e mudar hábitos, assim como, buscar alternativas de mitigação e/ou compensação dos impactos negativos decorrentes dos mais variados tipos de uso e ocupação desses espaços.

\section{Agradecimentos}

A equipe agradece a Coordenação de Aperfeiçoamento de Pessoal do Nível Superior pela concessão da bolsa de mestrado através do Programa de Pós-graduação em Geografia da Universidade Federal do Rio Grande do Norte, assim como ao Grupo de Pesquisa em Geoecologia e Biogeografia de Ambientes Tropicais (UFRN), pelo apoio nos trabalhos de campo e de gabinete. 


\section{Bibliografia}

BALVANERA, P. H.; COTLER, H. Estado y tendências do los servicios ecosistémicos, em Capital natural de México. Estado de conservación y tendências de cambio. Conabio: 185-245, 2009.

BANDARANAYAKE, W. M. Traditional and medicinal uses of mangroves. Mangroves and Salt Marshes, 2. 133148. 1998

BRASIL. Lei $n^{\circ} 8.349$, de 18 de julho de 2003. Cria a Reserva de Desenvolvimento Sustentável Estadual Ponta do Tubarão. Disponível em: <http://adcon.rn.gov.br/ACERVO/idema/DOC/DOC000000000043673.PDF> Acesso em: out 2016.

COMMON INTERNATIONAL CLASSIFICATION OF ECOSYSTEM SERVICES (CICES). Paper prepared for discussion at the expert meeting on ecosystem accounts organized by the UNSD, the EEA and the World Bank, London, 2010.

COSTA, D. F. S.; ROCHA, R. M.; CESTARO, L. A. Análise Fitoecológica e Zonação de Manguezal em Estuário Hipersalino. Mercator, v. 13, n. 1, p. 119-126, 2014.

DIAS, T. L. P.; ROSA, R. S.; DAMASCENO, L. C. P. Aspectos socioeconômicos, percepção ambiental e perspectivas das mulheres marisqueiras da Reserva de Desenvolvimento Sustentável Ponta do Tubarão (Rio Grande do Norte, Brasil). Gaia Scientia, v. 1, n. 1, p. 25-35, 2007.

FONSECA, S. M.; DRUMMOND, J. A. Reflorestamento de manguezais e o valor de resgate para o sequestro de carbono atmosférico. História, Ciências, Saúde: Manguinhos, v. 10, n. 03, 1071-1081, 2003.

HAINES-YOUNG, R. H.; POTSCHIN, M.B. Ecosystem services: Exploring a geographical perspective. Progress in Physical Geography, v. 35, n. 5, p. 575-594, 2011.

INSTITUTO DE DESENVOLVIMENTO SUSTENTÁVEL E MEIO AMBIENTE DO RIO GRANDE DO NORTE - IDEMA. Macau. Informativo Municipal, 1999.

MATTOS, P. P. KONIG, A. FREIRE, F.A.M. ALOUFA, M.A.I. Etnoconhecimento e percepção dos povos pesqueiros da Reserva Ponta do Tubarão acerca do ecossistema manguezal. Revista Brasileira de Biociências, $\mathrm{n}$. 10, p. 481-489. 2012.

MILLENIUM ECOSYSTEM ASSESSMENT (MEA). Ecosystem and human well-being: a framework for assessment. Washington: Island Press, 2003, 245 p.

NOBRE, I. M. Revelando os modos de vida da Ponta do Tubarão. 2005. Tese (Doutorado) - Programa de PósGraduação em Ciências Sociais, Universidade Federal do Rio Grande do Norte, Natal. 
QUEIROZ, R.N.M.; DIAS, T.L.P. Molluscs associated with the macroalgae of the genus Gracilaria (Rhodophyta): importance of algal fronds as microhabitat in a hypersaline mangrove in Northeastern Brazil. Braz. J. Biol. v. 74, n. 3, p. 52-63. 2014.

RABELO, M. S. A cegueira do óbvio: a importância dos serviços ecossistêmicos na mensuração do Bem-Estar. Tese (Doutorado). Programa de Pós-graduação em Desenvolvimento e Meio Ambiente, Universidade Federal do Ceará, 2014.

ROCHA JÚNIOR. J. M. Avaliação ecológica-econômica do manguezal de Macau/RN e a importância da aplicação de práticas preservacionistas pela indústria petrolífera local. Dissertação (Mestrado). Programa de Pós-graduação em Ciência e Engenharia de Petróleo, Universidade Federal do Rio Grande do Norte, 2011.

SUDENE, 1969. Cartas Topográficas. Escala 1:100.000. Folhas: SB-24-X-D-II Macau e SB-24-X-D-III São Bento do Norte. Região Nordeste do Brasil. MINTER - Superintendência do Desenvolvimento do Nordeste.

VANNUCCI, M. Os manguezais e nós: uma síntese de percepções. São Paulo: EDUSP, 2002. 244 p.

YE, Y., TAM N. F-Y., LU, C-Y., WONG, Y-S. Effects of salinity on germination, seedling growth and physiology of three salt-secreting mangrove species. Aquatic Botany, v. 83, 193-205. 2005. 